\title{
Morfologia e vascularização arterial das glândulas tireóides em gansos domésticos
}

Cheston César Honorato PEREIRA $^{1}$

Tatiana Carlesso dos SANTOS

Pedro Primo

BOMBONATTO ${ }^{2}$

Frederico Ozanam

CARNEIRO e SILVA ${ }^{3}$

Correspondência para:

CHESTON CÉSAR HONORATO PEREIRA Rua Prof. Mário Porto, 215 - Bairro Lídice 38400138 - Uberlândia - MC

Recebido para publicação: 12/05/2004 Aprovado para publicação: 23/08/2005

\author{
1 - Centro Regional Universitário de Espírito Santo do Pinhal, Espírito Santo \\ do Pinhal - SP \\ 2 - Departamento de Cirurgia da Faculdade de Medicina Veterinária e \\ Zootecnia da Universidade de São Paulo, São Paulo - SP \\ 3 - Instituto de Ciências Biomédicas da Universidade Federal de Uberlândia, \\ Uberlândia - MG
}

\section{Resumo}

Palavras-chave: Anatomia das aves.

Ganso

Objetivou-se estudar a morfologia e o comportamento das artérias que se destinam às glândulas tireóides, abordando seu número, origem e ordenação em 30 gansos domésticos (Anser domestica), injetados com Neoprene látex 450 corado e fixados em solução aquosa de formalina a 10\%. As glândulas tireóides apresentam-se pares, ovóides e localizam-se na extremidade cranial da cavidade tóracoabdominal, relacionam-se com o nervo vago, veia jugular e artéria carótida comum, e possuem em média de 0,97; 0,69 e 0,43 cm no antímero direito e 1,04; 0,62 e 0,38 cm no antímero esquerdo, para comprimento, largura e espessura, respectivamente. As glândulas tireóides recebem colaterais das artérias: carótida comum, cervical cutânea ascendente, esofagotraqueobronquial, esofágica ascendente, comum do nervo vago ipsilateralmente e ramo esofágico, sendo estes dois últimos somente para a glândula direita. O número de vasos variou de 1 a 5 vasos, sendo 2 vasos (15 casos, 50\% \pm 10 ) para o antímero direito e 3 vasos (12 casos, $40 \% \pm 9,8)$ para o antímero esquerdo, o padrão mais freqüentemente observado. As artérias tireóideas cranial, média cranial, média, média caudal e caudal estiveram presentes no antímero direito em 29, 8, 8, 14 e 29 gansos respectivamente, e no antímero esquerdo em 28, 5, 14, 5 e 28 gansos respectivamente. Um único ramo, a artéria tireóidea, destinou-se a glândula em um animal à direita e em dois animais a esquerda.

\section{Introdução}

Das parcimoniosas informações da literatura depreende no que as glândulas tireóides, em gansos, são órgãos pares e ovóides, de coloração castanho-avermelhada, com cerca de 11 a $15 \mathrm{~mm}$ de comprimento, 6 a $8 \mathrm{~mm}$ de largura e 2 a $3 \mathrm{~mm}$ de espessura ${ }^{1}$, localizadas nas proximidades da siringe, em posição caudal ao inglúvio nas galinhas, próximo à origem da artéria vertebral e relacionadas com a artéria carótida comum, veia jugular e nervo vago, ipsilateralmente ${ }^{2,3}$. Nas galinhas $(\text { Gallus gallus })^{4} \mathrm{O}$ tamanho glandular depende de vários fatores, como local de origem, sexo, clima, dieta e atividade da ave ${ }^{5}$.
Com relação à vascularização desta glândula cita-se a existência, para o gênero Anser, de 03 artérias, sendo elas denominadas cranial, caudal e média. A origem dessas artérias é variável, podendo emergir das artérias carótida comum, comum do nervo vago, esofagotraqueobronquial, esofágica ascendente e raramente da artéria tronco braquiocefálico ${ }^{5}$.

Pode-se observar uma inter-relações entre as artérias carótidas e vertebral, em pombos domésticos e outras aves, indicando que a artéria comum do nervo vago é responsável pela irrigação do esôfago, inglúvio, traquéia, timo, nervo vago, tegumento cervical, musculatura axial em 
particular as glândulas tireóides ${ }^{6}$, cuja origem é variada e pode ser executada em Gallus, por 1 ou até 5 colaterais.

A irrigação das glândulas tireóides, em Gallus $^{2}$, pode ser executada por 1 ou ate 5 colaterais, de origens diferentes. Getty ${ }^{4}$ estudando o sistema arterial de galinhas, informa que a artéria tireóidea cranial pode originar-se das artérias vertebral ou artéria do vago, enquanto a artéria tireóidea caudal pode surgir da carótida comum ou esofágica ascendente. $\mathrm{O}$ autor cita ainda que em alguns casos a glândula tireóide pode penetrar no tecido do timo.

Assim, considerando o papel das glândulas tireóides no metabolismo das aves, tornam-se imprescindíveis estudos sobre suas características anatômicas, de tal sorte que o presente trabalho objetiva estudar a morfologia das referidas glândulas, enfatizando o comportamento das artérias, relativamente ao seu o número, origem e ordenação em gansos domésticos (Anser domestica).

\section{Materiais e métodos}

Para a realização deste trabalho utilizou-se 30 gansos domésticos, adultos, sendo 19 machos e 11 fêmeas, obtidos em fazendas da região de Espírito Santo do Pinhal, SP. O óbito dos animais foi induzido por aprofundamento do plano de anestesia, por inalação de clorofórmio. A seguir os animais tiveram o sistema arterial preenchido por Neoprene látex 450, corado, através de injeção na artéria isquiática, após o que os animais foram fixados por imersão e injeção intramuscular de solução aquosa de formalina a $10 \%$.

A entrada da cavidade tóracoabdominal foi exposta pelo afastando do osso esterno, clavícula e musculatura para identificação e mensuração das glândulas tireóideas e anotações da origem, número e ordenação dos ramos colaterais arteriais que a elas se destinam.

A origem de cada ramo foi então estabelecida e foram tomados o com- primento (crânio-caudal), largura (láteromedial) e espessura (dorso-ventral) de cada glândula com o auxílio de um paquímetro. Para documentação dos resultados obtidos foram confeccionados esquemas de todas as preparações e tomadas algumas fotografias. Os termos anatômicos foram baseados na Nomina Anatomica Avium, proposta por $\mathrm{Baumel}^{7}$

\section{Resultados}

As glândulas tireóides apresentaramse pares, ovóides, de coloração castanho avermelhado, localizadas próximas ao limite cranial da cavidade torácica, lateroventralmente ao esôfago e traquéia e cranialmente a siringe, mantendo estreita relação com o nervo vago, veia jugular e artéria carótida comum.

A topografia das glândulas, em cada antímero variou, de forma que em 6 animais $(20 \%$ ? 8) elas encontravam-se simetricamente dispostas, e em $24(80 \%$ ? 8) afastando-se cranial ou caudalmente uma da outra. Em 12 animais (40\% ? 9,8), ipsilateralmente, notamos que a tireóide em sua margem caudal encontrava-se ligada ao tecido da glândula paratireóide e ao corpo último branquial.

Quanto às dimensões das glândulas, notamo-las com 0,66 a $1,21 \mathrm{~cm}$ de comprimento (média de $0,97 \mathrm{~cm}$ ), 0,54 a $0,88 \mathrm{~cm}$ de largura (média de $0,69 \mathrm{~cm}$ ) e 0,21 a $0,65 \mathrm{~cm}$ de espessura (média de 0,43 $\mathrm{cm})$ para aquelas localizadas no antímero direito e de 0,76 a 1,32 $\mathrm{cm}$ de comprimento (média de 1,04 cm), 0,32 a 0,87 cm de largura (média de $0,62 \mathrm{~cm}$ ) e 0,21 a $0,54 \mathrm{~cm}$ de espessura (média de $0,38 \mathrm{~cm}$ ) para as glândulas do antímero esquerdo.

As artérias foram denominadas de acordo com sua posição no animal, ou seja, quando ocorreu 1 artéria, essa foi denominada de artéria tireóidea, quando duas: artérias tireóideas cranial e caudal, quando três: artérias tireóideas cranial, média e caudal, quando quatro: artérias tireóideas cranial, média cranial, média caudal e caudal e 
finalmente quando ocorreram cinco estas foram denominadas de artérias tireóideas cranial, média cranial, média, média caudal e caudal.

O número de vasos destinados à glândula tireóide direita variou de 1 a 5 , sendo 1 vaso em 1 caso $(3,3 \% \pm 3,6) ; 2$ vasos em 15 casos $(50 \% \pm 10) ; 3$ e 4 vasos em 6 casos $(20 \% \pm 8)$ e 5 vasos em 2 casos $(6,7 \%$ $\pm 5)$.

Já, a glândula tireóide esquerda apresentou: 1 vaso em 2 casos (6,7\% \pm 5$) ; 2$ vasos em 11 casos $(36,7 \% \pm 9,6) ; 3$ vasos em 12 casos ( $40 \% \pm 9,8)$; 4 vasos em 3 casos $(10 \% \pm 9,4)$; e 5 vasos em 2 casos $(6,7 \% \pm$ 5). Em 11 casos (36,7\% 9,6) número de artérias foi igual para os dois antímeros concomitantemente, sendo mais freqüentemente 2 vasos à direita e 3 vasos à esquerda.

Portanto as artérias tireóideas cranial, média cranial, média, média caudal e caudal estiveram presentes no antímero direito em 29, 8, 8, 14 e 29 gansos respectivamente, e no antímero esquerdo em $28,5,14,5$ e 28 gansos respectivamente. A artéria tireóidea foi observado em um animal a direita e em dois animais a esquerda.

\section{Origem das artérias tireóideas}

Para o antímero direiro observou-se: A artéria tireóidea cranial direita, presente em 28 animais $(96,7 \% \pm 3,6)$, emergiu 16 vezes da artéria cervical cutânea ascendente direita $(53,3 \% \pm 10) ; 5$ vezes do ramo esofágico direito $(16,7 \% \pm 7,5) ; 4$ vezes da artéria esofágica ascendente direita (13,3\% $\pm 6,8) ; 3$ vezes da artéria carótida comum direita $(10 \% \pm 6)$; e uma vez da artéria comum do nervo vago direita $(3,3 \% \pm 3,6)$.

Artéria tireóidea direita, no único caso em que surgiu $(3,3 \% \pm 3,6)$, originou-se na artéria carótida comum direita.

A artéria tireóidea média cranial, nas 8 observações em que ocorreu $(26,7 \pm 8,8)$, 7 vezes se originou da artéria cervical cutânea ascendente direita $(23,3 \% \pm 8,5)$ e 1 vez do ramo esofágico direito $(3,3 \% \pm 3,6)$.

A artéria tireóidea média, presente em
8 casos $(26,7 \pm 8,8)$, emergiu 5 vezes da artéria cervical cutânea ascendente direita $(16,7 \% \pm 7,5)$ e 1 vez das artérias carótida comum, esofágica ascendente direita e ramo esofágico direito $(3,3 \% \pm 3,6)$.

A artéria tireóidea média caudal direita, vista em 8 casos $(26,7 \pm 8,8)$, originouse 7 vezes da artéria cervical cutânea ascendente direita $(23,3 \% \pm 8,5)$ e 1 vez do ramo esofágico direito $(3,3 \% \pm 3,6)$.

A artéria tireóidea caudal direita, identificada em 29 casos $(96,7 \% \pm 3,6)$, emergiu 20 vezes da artéria esofagotraqueobronquial direita $(66,7 \% \pm 9,4), 5$ vezes da artéria cervical cutânea ascendente direita $(16,7 \% \pm 7,5)$ e 2 vezes da artéria esofágica ascendente e ramo esofágico $(6,7 \%$ $\pm 5)$.

\section{Para o antímero esquerdo observou-se:}

Nos dois casos $(6,7 \% \pm 5,0)$, em que a artéria tireóidea esquerda apareceu originou-se artéria esofagotraqueobronquial ou na artéria esofágica ascendente.

A artéria tireóidea cranial esquerda, presente em 28 animais $(93,3 \% \pm 5,0)$, emergiu 19 vezes da artéria esofágica ascendente esquerda $(63,3 \% \pm 9,6), 4$ vezes da artéria carótida comum esquerda $(13,3 \%$ \pm 6,8), 3 vezes da artéria cervical cutânea ascendente esquerda $(10 \% \pm 6)$ e 2 vezes do ramo esofágico esquerdo $(6,7 \% \pm 5,0)$.

A artéria tireóidea média cranial esquerda, das 5 observações em que ocorreu $(16,7 \% \pm 7,5), 4$ vezes originou- se da artéria esofágica ascendente esquerda $(13,3 \% \pm 6,8)$ e 1 vez da artéria cervical cutânea ascendente esquerda $(3,3 \% \pm 3,6)$. Já a artéria tireóidea média esquerda, que ocorreu em 14 casos $(46,7 \pm 10,0)$, emergiu 11 vezes da artéria esofágica ascendente esquerda $(36,7 \% \pm 9,6)$, 2 vezes da artéria esofagotraqueobronquial esquerda $(6,7 \% \pm 5)$ e 1 vez da artéria cervical cutânea ascendente esquerda $(3,3 \% \pm 3,6)$.

A artéria tireóidea média caudal esquerda, nos 5 casos observados $(16,7 \% \pm$ $7,5)$, originou-se 4 vezes da artéria esofágica ascendente esquerda $(13,3 \% \pm 6,8)$ e 1 vez da artéria cervical cutânea ascendente 


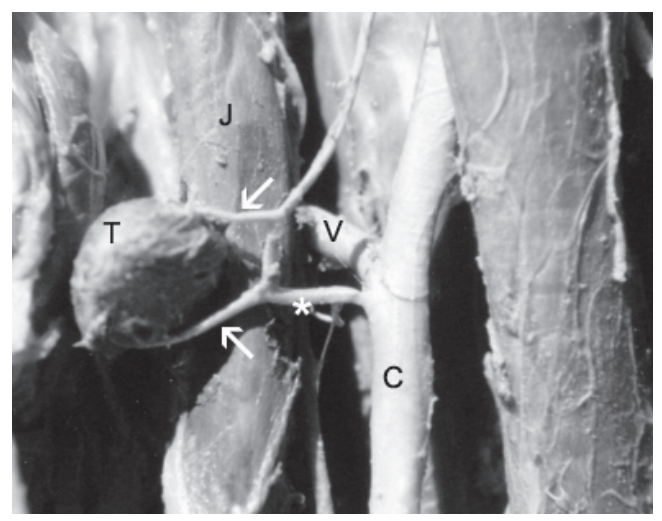

Figura 1 - Fotografia das artérias tireóideas cranial ecaudal (setas) dirigindose à glândula tireóide esquerda $(T)$, as quais originaram-se da artéria esofágica ascendente $(*)$, que por sua vez é ramo da artéria esofágica ascendente $(*)$, que por sua vez é ramo da
artéria carótida comum (C). E) esôfago, J) veia jugular e V) artéria vertebral

esquerda $(3,3 \% \pm 3,6)$.

A artéria tireóidea caudal esquerda, nos 28 casos identificados $(93,3 \% \pm 5,0)$, emergiu 21 vezes da artéria esofagotraqueobronquial esquerda $(70 \% \pm 9,2), 6$ vezes da artéria esofágica ascendente esquerda $(20 \% \pm 8)$ e 1 vez do ramo esofágico esquerdo $(3,3 \% \pm 3,6)$.

\section{Discussão}

No referente a morfologia e topografia das glândulas tireóides de gansos domésticos de forma geral, devemos concordar com os dados fornecidos pelos autores consultados ${ }^{1,2,3,4}$, quando estes descrevem-na, porém destacamos que estes autores não indicam a possibilidade destas glândulas mostraram-se assimétricas quando comparada a posição em cada antímero.

No tocante a esse aspecto, somente King e McLelland ${ }^{5}$ (1981) citaram as diferentes posições que as glândulas podem assumir, entretanto sem se ocuparem de uma descrição mais minuciosa das variações. Com relação às dimensões, apresentadas por Nickel,Schummer e Seiferle ${ }^{1}$ devemos ressaltar que as diferenças encontradas, talvez sejam devido ao tipo de fixação do material, que não foi citado pelos referidos autores além disso, devemos lembrar das observações feitas por King e McLelland ${ }^{5}$ cujo relato indicam que o tamanho da glândula depende de A literatura cita que a glândula tireóide pode penetrar no tecido do timo ${ }^{4}$, fato esse que não foi observado em nossa pesquisa, em que a glândula permaneceu individualizada, em todos os casos. Aquela ocorrência pode ser uma determinante de corrente da espécie de ave analisada.

De acordo com a Nomina Anatomica Avium $^{7}$ nas aves em geral a artéria carótida comum divide-se em artéria carótida interna, tronco vertebral e artéria comum do nervo vago, além de originar as artérias esofagotraqueobronquial e tireóidea. A artéria esofagotraqueobronquial ou também chamada artéria siringotraqueobronquial origina-se na face medial da artéria carótida comum (gêneros Gavia, Larus, Phoenicopterus, Gallus, Brnata, Trogon e Alcedo), no tronco vertebral (gênero Perisoreus), ou na artéria carótida comum de um antímero e o no tronco vertebral contralateral (gêneros Spheniscus e Corvus). Geralmente esta artéria distribui-se para a traquéia caudal e siringe, brônquios principais, pericárdio e esôfago. Em algumas espécies pode ser responsável pelo suprimento sanguíneo da tireóide, paratireóides, corpo ultimobronquial e corpo carotídeo.

Ainda segundo a Nomina Avium, as artérias tireóideas podem variar de uma a três, designadas de acordo com sua posição, a caudal, ou nos casos em que é única, pode originar-se das artérias carótida comum, vertebral, porção proximal da esofagotraqueobronquial, comum do nervo vago, porção terminal do tronco braquiocefálico ou da artéria subclávia. A artéria tireóidea cranial, geralmente, é oriunda das artérias comum do nervo vago, carótida comum ou esofágica ascendente.

Os vasos destinados à glândula tireóide, independente do antímero considerado, tiveram sua origem nas artérias carótida comum, esofagotraqueobronquial, esofágica ascendente, comum do nervo vago, cervical cutânea ascendente e ramo 
esofágico. Devemos observar que os autores compulsados não citam essas duas últimas artérias, sendo que no nosso material o ramo esofágico é proveniente diretamente da artéria carótida comum, diferindo da artéria esofágica ascendente.

Nos pombos ${ }^{6,8}$ é citado somente a artéria comum do nervo vago e em galinhas ${ }^{1,3,9}$ há referência apenas a artéria carótida comum, não especificando outros ramos, o que difere dos nossos achados, considerando as espécies estudadas.

Em pombos, na região da glândula tireóide, a artéria carótida comum se divide em três ramos, a artéria vertebral, carótida interna e comum do nervo vago, sendo que esta última irriga a glândula tireóide, inglúvio e região subescapular e ainda emite as artérias esofágica ascendente para a porção anterior do esôfago e cervical cutânea para a pele da região do pescoço, se tornando extremamente delgada no terço médio do pescoço ${ }^{10}$.

Em galinhas o arco da aorta origina a artéria braquiocefálica esquerda ${ }^{9}$, sendo a direita mais cranial. De cada artéria surgem uma artéria carótida comum, direcionada à cabeça, que por sua vez da origem às artérias traqueal, esofágica ascendente, tireóideas cranial e caudal e vertebral. Além das artérias carótida comum, comum do nervo vago, esofagotraqueobronquial e esofágica ascendente.

Para origens das artérias destinadas à glândula tireóide cita-se em galinhas a artéria tronco braquiocefálico ${ }^{5}$, em pombos ${ }^{8}$ a artéria ingluvial e nas aves em geral, além da artéria tronco braquiocefálico, a artéria subclávia ${ }^{7}$. Já, Getty ${ }^{4}$ cita além das artérias carótida comum, esofágica ascendente e comum do nervo vago (por esse autor denominada artéria do vago), a artéria vertebral.

Em Gallus gallus da Linhagem Peterson $^{2}$ são citadas as artérias carótida comum, comum do nervo vago e esofágica ascendente, as quais também foram por nós relacionadas. Os autores acrescentam ainda as artérias ingluvial, subclávia, vertebral e aorta ascendente como origens das artérias que suprem a glândula tireóide. Com relação a essas últimas artérias, não encontramos vasos arteriais destinados a ela, mas podemos aludir que o ramo esofágico encontrado em nossa pesquisa seja o equivalente a artéria ingluvial, já que em gansos domésticos, não observamos um inglúvio desenvolvido como nos Gallus gallus.

No mesmo trabalho, os autores encontraram um maior número de vasos destinados à glândula tireóide direita originados da artéria ingluvial e um menor número de vasos da artéria aorta ascendente e subclávia. Nesta pesquisa, em gansos, observamos que um maior número de vasos é cedidos para a tireóide pela artéria cervical cutânea ascendente e em menor número pela artéria comum do nervo vago.

Para o antímero esquerdo Gonçalvez et $\mathrm{al}^{2}$ encontraram um maior número de artérias provenientes da artéria esofágica ascendente, o que vem a concordar com os dados desta pesquisa, mas para o menor número de vasos cedidas por uma artéria à glândula os autores citam a artéria vertebral, ao passo em gansos encontramos o ramo esofágico.

Glenny ${ }^{11}$ descreve em seus esquemas em aves da ordem dos Anseriformes que a glândula tireoóde é vascularizada por uma artéria originada da artéria cervical superficial ou diretamente da artéria carótida interna. Já em aves da ordem dos Galiformes, que inclui as galinhas de um modo geral, pavões e faisões, Glenny ${ }^{12}$ descreve que a artéria tireóidea pode originar-se diretamente da artéria subclávia, da artéria carótida comum e da artéria cervical superficial. Nos galos silvestres (Bonasa umbellus) a tireóide é vascularizada por dois pequenos ramos originados da artéria carótida comum e da artéria cervical superficial. $\mathrm{O}$ autor cita uma artéria denominada arteria ventralis gallinae de onde surgem ramos tireóideos nos perus e faisões

Para 46,7\% dos casos estudados, os mesmos autores encontraram uma simetria no arranjo vascular, com maior freqüência 
de 2 artérias, por nossa vez, encontramos tal simetria em 36,7\%, com maior freqüência de 2 artérias.

Em dois casos, ocorrendo isoladamente em cada um dos antímeros, encontramos um número de cinco vasos irrigando a glândula, mas nesses casos, as artérias que se apresentaram foram mais delgadas quando comparadas aquelas dos demais casos. Essa informação coaduna com as observações desses autores que encontraram apenas um caso com cinco artérias. Perceberam também, um número mais freqüente de 2 artérias tireóideas, enquanto notamos um número mais freqüente de duas artérias para a glândula direita e 3 artérias para a esquerda.

Os casos arteriais destinados à tireóide dispuserem-se, sempre, respeitando seu antímero, não havendo a passagem de artérias de um antímero para o outro, o que concorda ainda com os dados desses autores, demonstrando haver independência entre os antímeros. Tal fato parece ser decorrente da relação sintópica da glândula com o emaranhado de casos adjacentes.

\section{Conclusões}

Após análise dos nossos resultados e confrontação com os achados de outros autores, podemos concluir que:

1.As glândulas tireóides são pares, ovóides de coloração castanho avermelhada, quando fixadas e conservadas em solução de formol a $10 \%$, encontram-se localizadas na extremidade cranial da cavidade toracoabdominal, relacionam-se com o nervo vago, veia jugular e artéria carótida comum e com topografia, em cada antímero, variável;

2.As glândulas podem possuem em média $0,97 \mathrm{~cm}, 0,69 \mathrm{~cm}$ e $0,43 \mathrm{~cm}$ para aquelas localizadas no antímero direito e $1,04 \mathrm{~cm}$, $0,62 \mathrm{~cm}$ e $0,38 \mathrm{~cm}$ para as outras do antímero esquerdo; para comprimento, largura espessura respectivamente.

3.As artérias foram denomi-nadas de acordo com sua posição no animal em artéria tireóidea e artérias tireóideas cranial, média cranial, média, média caudal e caudal;

4.As glândulas tireóides direita e esquerda são vascularizadas pelas artérias carótida comum, cervical cutânea ascendente, esofagotraqueobronquial, esofágica ascendente, comum do nervo vago ou pelo ramo esofágico, sendo mais freqüentemente imergida à direita pela cervical cutânea ascendente e menos pela comum do nervo vago e à esquerda pelos ramos da artéria esofágica ascendente e ramo esofágico respectivamente.

\section{Arterial vascularization and morphology of the thyroid glands in domestic geese}

\section{Abstract}

The present work aimed to study the morphology of the thyroid glands and the arterial behavior of their arteries, emphasizing number, origin and ordination of the vases in 30 domestic geese (Anser tames domestica). The animQals were injected with Neoprene latex " 450 " red-faced with specific pigment through the sciatic artery and fixed in aqueous solution of formalin $10 \%$. In the animals studied the thyroid glands are even, oval and, when fixed, they have red chestnut color. These glands are located in the cranial extremity of the thoracoabdominal cavity, linked with the vague nerve, jugular vein and common carotid artery and their topography may be variable in each antimere. The thyroid glands have in average $0.97,0.69$ and $0.43 \mathrm{~cm}$ in right side and 1.04, 0.62 and $0,38 \mathrm{~cm}$ in left side, to length, width and thickness, respectively. The arteries responsible to emit colateral branches to thyroid glands are: common cutaneous carotid arteries, cervical
Key-words:

Anatomy of birds.

Geese.

Artery.

Thyroid gland. 
cutaneous ascendant, esophageal tracheal bronchial, esophageal ascendant, common of the vague nerve ipsilaterally and also for the branch esophageal, being these last ones only happened for the right gland. The vases number varied from 1 to 5 , being 2 vases $(15$ cases, $50 \%$ ? 10) for the right antimere and 3 vases (12 cases, $40 \%$ ? 9,8), the model more frequently observed. The cranial, cranial middle, middle, caudal middle and caudal thyroid arteries were present in the right side in 29, 8, 8, 14 e 29 geese respectively, and in the left side in 28, 5, 14,5 e 28 geese respectively. This was a unique vessel to gland, the thyroid artery, in one animal to right and in two animals to left side.

\section{Referências}

6 BAUMEL, J. J. Vertebral-dorsal carotid artery interrelationships in the pigeon and other birds. Anat. Anz., v. 114, p. 113-130, 1964

7 BAUMEL, J. J Handbook of avian anatomy: nomina anatomica avium. London: Academic Press, 1979. p. 355-365.

8 BADHURI, J. L.; BISWAS, B. The main cervical and thoracic arteries of birds. Series 2. Columbiformes, Columbidae, part 1. Anat. Anz., p. 337-350, 1954.

10 BADHURI, J. L.; BISWAS, B.; DAS, S. K. The arterial system of the domestic pigeon (Columba livia Gmelin). Anat. Anz, v. 104, p. 1-14, 1957.

4 GETTY, R. Sisson/Grossman's anatomia dos animais domésticos. 5. ed. Rio de Janeiro: Interamericana, 1981. 2, p. $1840-1856$

11 GLENNY, F. H. A systematic study of the main arteries in the region of the heart. Aves VIII. Anseriformes, Part 1. Canadian Journal Research, v. 22, n. 2, p. 17-35, 1944.

12 GLENNY, F. H. A systematic study of the main arteries in the region of the heart. Aves XII. Galliformes, Part 1. Ohio Journal Science, v. 51, p. 47-54. 1951.

2 GONÇALEZ, P.O.et al. Suprimento arterial das glândulas tireóides em Gallus gallus da linhagem Peterson. Arq. Ciên. Vet. Zool. UNIPAR, v. 2, n. 2, p. 113-117, 1999.

5 KING, A. S.; MCLLELAND, J. Form and Function in Birds. V.2. London: Academicpress, 1981.v.2, p. 150160.

$9 \mathrm{KOCH}, \mathrm{T}$. Anatomy of the chicken and domestic birds. lowa: lowa Sate University Press, 1973.p.103-52.

1 NICKEL, R.; SCHUMMER, A.; SEIFERLE, E. Anatomy of the domestic birds. Berlin:Parey, 1977. p. 92-111.

3 SCHWARZE, E.; SCHRODER, L. Compendio de anatomia veterinária. Zaragoza: Acríbia,v.5,1970. p. 142. 